Acta Crystallographica Section D

Biological

Crystallography

ISSN 0907-4449

\title{
Crystallization and preliminary diffraction data of a platelet-aggregation inhibitor from the venom of Agkistrodon piscivorus piscivorus (North American water moccasin)
}

\author{
R. K. Arni, ${ }^{a}$ K. P. Padmanabhan ${ }^{b}$ \\ and A. Tulinsky ${ }^{b_{*}}$
}

\begin{abstract}
${ }^{a}$ Department of Physics, IBILCE/UNESP, CP 136, São Jose do Rio Preto-SP, CEP 15054-000, Brazil, and ${ }^{\mathbf{b}}$ Department of Chemistry, Michigan State University, E. Lansing, MI 48824-1322, USA
\end{abstract}

Correspondence e-mail: tulinsky@cem.msu.edu
Applaggin (Agkistrodon piscivorus piscivorus platelet-aggregation inhibitor) is a potent inhibitor of blood platelet aggregation derived from the venom of the North American water moccasin. The protein consists of 71 amino acids, is rich in cysteines, contains the sequencerecognition site of adhesion proteins at positions 50-52 (Arg-Gly-Asp) and shares high sequence homology with other snake-venom disintegrins such as echistatin, kistrin and trigramin. Single crystals of applaggin have been grown and X-ray diffraction data have been collected to a resolution of $3.2 \AA$. The crystals belong to space group $P 4_{1} 22$ (or its enantiomorph), with unit-cell dimensions $a=b=63.35, c=74.18 \AA$ and two molecules per asymmetric unit. Molecular replacement using models constructed from the NMR structures of echistatin and kistrin has not been successful in producing a trial structure for applaggin.
Received 5 March 1999 Accepted 5 May 1999

\section{Introduction}

Cell-matrix and cell-cell adhesion is mediated by surface receptors called integrins. The natural ligands of integrins are large proteins with complex functions, which facilitate communication between the interior and exterior of the cell. The main recognition site in many of these protein ligands is a simple sequence of arginine, glycine and aspartic acid (Ruoslahti \& Pierschbacher, 1987); the cellbinding activity of such extracellular proteins can be stimulated by small synthetic peptides containing the RGD sequence. An essential factor in platelet aggregation is the interaction of fibrinogen with specific receptors associated with the glycoprotein IIb-IIIa (GPIIb-IIIa) complex. Unstimulated platelets do not aggregate in circulation since they do not bind fibrinogen. Antagonists such as ADP, epinephrine, thrombin or prostaglandin endoperoxides stimulate platelets exposing fibrinogen receptors associated with the GPIIb-IIIa complex, which results in fibrinogen binding and subsequent platelet aggregation. The interaction of platelet receptors expressed on the GPIIb-IIIa complex by fibrinogen can be inhibited by disintegrins, which bind to the integrin GPIIb-IIIa receptor on the platelet surface and inhibit aggregation induced by ADP, thrombin, platelet-activating factor and collagen.

Snake venoms are complex mixtures of proteins such as metalloproteinases, thrombinlike enzymes, phospholipases and disintegrins. The latter are small proteins consisting of 49-83 amino acids with a high content of cysteines, all of which are involved in the formation of disulfide bonds. Alignment of the sequences of snake-venom disintegrins demonstrates high sequence homology and conservation in the positions of the cysteines. Disintegrins contain an RGD sequence, which forms the recognition site of many adhesion proteins, and the RGD sequence of disintegrins has been postulated to interact with the GPIIb-IIIa complex. The disintegrin motif is also encountered in snake-venom zinc metalloproteinases (Calvete et al., 1991), which consist of a C-terminal catalytic domain fused to a disintegrin domain. It has been suggested that these proteinases are cleaved to liberate the disintegrin domain. The $\beta$-subunit of guinea-pig sperm surface protein PH30 (Blobel et al., 1992) and the mammalian epididymial protein 1 (Perry et al., 1992) also contain $\mathrm{N}$-terminal disintegrin domains.

Applaggin (Agkistrodon piscivorus piscivorus platelet aggregation inhibitor) is a potent inhibitor of blood platelet activation and secretion reactions, blocking platelet aggregation at nanomolar concentrations. However, unlike other snake-venom disintegrins such as echistatin (Saudek et al., 1991; Chen et al., 1991), kistrin (Adler \& Wagner, 1992) and trigramin (Huang et al., 1989), applaggin migrates as a $17700 \mathrm{Da}$ dimer under nonreducing electrophoretic conditions and as a $9800 \mathrm{Da}$ monomer in the presence of thiol (Chao et al., 1989). Thus, it would appear to be a dimer of identical subunits linked by at least two disulfide bridges. Although the NMR structures of echistatin and kistrin have been reported, no crystal structure of a disintegrin
(C) 1999 International Union of Crystallography Printed in Denmark - all rights reserved 
Table 1

Data-processing statistics.

\begin{tabular}{lccl}
\hline Resolution $(\AA)$ & $R_{\text {merge }}$ & $I / \sigma(I)$ & Completeness $(\%)$ \\
\hline 5.50 & 3.3 & 19.0 & 93 \\
4.36 & 9.4 & 7.7 & 85 \\
3.81 & 15.9 & 4.6 & 74 \\
3.46 & 37.3 & 2.0 & 51 \\
3.20 & 53.7 & 1.1 & 29 \\
\hline
\end{tabular}

has yet been determined. We have grown single crystals of applaggin, and an X-ray diffraction data set has been measured to $3.2 \AA$ resolution.

\section{Experimental procedures}

\subsection{Protein purification}

The purification procedure of applaggin has been described previously (Chao et al., 1989) and will only be summarized briefly here. Lyophilized venom from A. piscivorus piscivorus (water moccasin or cottonmouth snake) was obtained from the Miami Serpentarium Laboratories (Salt Lake City, UT). The crude venom was fractionated by molecular-sieve chromatography on a column of Sephadex G-50. Contaminating protein was removed by adsorption on a cation-exchange column (S-Sepharose) and antiplatelet activity was recovered in the effluent. The applaggin was then purified to greater than $90 \%$ by reverse-phase HPLC. This method of purification yielded $3 \mathrm{mg}$ of applaggin from $1 \mathrm{~g}$ crude snake venom.

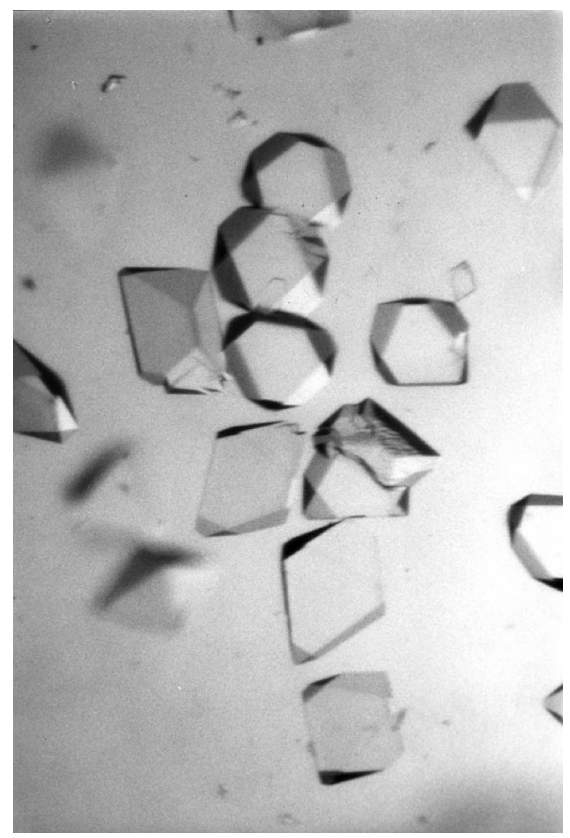

Figure 1

Photograph of crystals of applaggin from the venom of A. piscivorus piscivorus. Maximum dimension is about $0.4 \mathrm{~mm}$.

\subsection{Crystallization}

A lyophilized applaggin protein sample was dissolved in doubly distilled water at a concentration of $15.2 \mathrm{mg} \mathrm{ml}^{-1}$. Crystallization was performed by the hanging-drop vapor-diffusion method using 24-well tissueculture plates. Initial trials were carried out with a screen similar to the one described by Jancarik \& Kim (1991). Typically, $1 \mu$ drops of protein solution were mixed with an equal volume of the screening solution and equilibrated over $1 \mathrm{ml}$ of the latter as reservoir solution. The conditions were refined by trial-and-error, and single crystals $(\sim 0.3 \mathrm{~mm}$ in each dimension) were obtained when a $2 \mu \mathrm{l}$ protein droplet was mixed with an equal volume of reservoir solution consisting of $0.1 \mathrm{M}$ sodium acetate $(\mathrm{pH} 4.6)$ and $1.5 \mathrm{M}$ ammonium phosphate (Fig. 1).

\subsection{X-ray diffraction data collection}

Crystals of applaggin were mounted in thin-walled glass capillaries and were examined with $\mathrm{Cu} K \alpha$ radiation generated by a Rigaku RU-200 rotating-anode generator operating at $50 \mathrm{kV}$ and $80 \mathrm{~mA}$ equipped with a graphite monochromator. Diffraction intensities were measured at room temperature using a Siemens X1000 multiwire detector set at a distance of $11.6 \mathrm{~cm}$ from the crystal with an oscillation range of $0.2^{\circ}$ per image. The crystals diffracted $\mathrm{X}$-rays to a maximum resolution of $3.2 \AA$. A processed data set was obtained from 500 frames by use of the program XENGEN (Howard et al., 1987). A total of 21478 reflections was measured (overall redundancy of 7.2) with a redundancy of 5.0 in the last resolution shell (3.5-3.2 $\AA$ ). Other pertinent data-processing statistics are presented in Table 1.

\section{Results}

The amino-acid sequences of disintegrins which inhibit fibrinogen interaction with platelet receptors from a number of different snake species such as applaggin, echistatin, kistrin and trigramin have been determined. These disintegrin domains are also encountered in snake-venom zinc metalloproteinases (Calvete et al., 1991), the $\beta$ subunit of guinea-pig sperm surface protein PH30 (Blobel et al., 1992) and mammalian epididymial protein 1 (Perry et al., 1992). The positions of the six disulfides are conserved in snake-venom disintegrins, except in the case of echistatin, which only has four (Dennis et al., 1990). The behavior of applaggin in non-denaturing SDS gels, where it migrates as a $17700 \mathrm{Da}$ polypeptide and as a $9800 \mathrm{Da}$ peptide under reducing conditions, has been attributed to the existence of a disulfide-linked dimer (Chao et al., 1989).

Single crystals of applaggin grew to a maximum size of $0.3 \mathrm{~mm}$ in about $4 \mathrm{~d}$ (Fig. 1). The crystals belong to the tetragonal crystal system with unit-cell dimensions $a=b=63.39, c=73.35 \AA$, space group $P 4_{1} 2{ }_{1} 2$ or enantiomorph, with two molecules in the asymmetric unit and $V_{M}=2.5 \AA^{3} \mathrm{Da}^{-1}$ (51\% protein fraction). Of the 12180 observations with $I>2 \sigma(I)$ processed to $3.2 \AA$ resolution, 1840 independent reflections had an $R_{\text {merge }}$ of $7.2 \%$ (average redundancy 6.6 , resulting in $69 \%$ compleness).

Applaggin (71 residues) and kistrin (68 residues) have $75 \%$ sequence identity, while that of applaggin and trigramin (71 residues) is $83.3 \%$; applaggin and echistatin (49 residues) are only $59 \%$ identical. Rotationtranslation molecular-replacement methods have been applied to the applaggin diffraction data using the NMR coordinates of kistrin as a model (Adler \& Wagner, 1992). The NMR structures of both kistrin and echistatin (Saudek et al., 1991) have little regular secondary structure. Of the 68 residues of kistrin, 25 were not assigned (38\%), while the remainder had an average r.m.s. deviation from the average structure of $1.1 \AA$, with the RGD triplet in a flexibly disordered region; with echistatin, about 25 of the residues were not assigned $(50 \%)$, including the RGD region. A self-rotation calculation made with the program AMoRe (Navaza, 1994) produced a solution confirming the presence of two monomers per asymmetric unit. Cross-rotation calculations using the kistrin NMR structure as a search model and the programs MERLOT (Fitzgerald, 1988), AMoRe and X-PLOR (Brünger, 1992) did not provide consistent solutions. A large number of different models (about 30) were examined, ranging from only the main-chain atoms of kistrin, to deleting questionable regions, to using the average model of eight NMR structures. The different solutions, however, did not remain significant among different models or with respect to changes in calculation parameters such as resolution range or radius of integration. The highest cross-rotation solutions were also used in translation searches in both enantiomorphic space groups without success. Similar analyses were conducted with echistatin atomic coordinates, even though it is $25 \%$ smaller than applaggin and kistrin, without providing positive results.

The failure of molecular-replacement methods to solve the structure of applaggin 
comes as a surprise considering the high sequence identity between applaggin and kistrin. This could be because of the low resolution of the X-ray diffraction data which, in view of the size of the crystals, is disappointing for a protein so small. It could also be the result of a somewhat different structure from those of the two disintegrins, which are additionally flexible and disordered in solution. The poor diffraction of the large applaggin crystals reflects the solution behavior seen by NMR. If this is not the case, mirror optics or synchrotron data coupled with cryocrystallography might be useful in ultimately resolving the structure of applaggin.

We are grateful to Dr J. Maranganore (Biogen), Cambridge, MA for the sample of applaggin from Biogen used in this study. This research was supported by NIH grant HL25942 to AT and by grants from FAPESP and CNPq (Brazil) to RKA.

\section{References}

Adler, M. \& Wagner, G. (1992). Biochemistry, 31, 1031-1039.

Blobel, C. P., Wolfsberg, T. G., Turck, C. W., Myles, D. G., Primakoff, P. \& White, J. M. (1992). Nature (London), 356, 248-252.

Brünger, A. T. (1992). X-PLOR Version 3.1. A System for Crystallography and NMR. New Haven: Yale University Press.

Calvete, J. J., Schaefer, W., Soszka, T., Lu, W., Cook, J. J., Jameson, B. A. \& Niewiarowski, S. (1991). Biochemistry, 30, 5225-5229.

Chao, B. H., Jakubowski, J. A., Savage, B., PingChow, E., Marzec, U. M., Harker, L. A. \& Maraganore, J. M. (1989). Proc. Natl Acad. Sci. USA, 86, 8050-8054.
Chen, Y., Pitzenberger, S. M., Garsky, V. M., Lumma, P. K., Sanyal, G. \& Baum, J. (1991). Biochemistry, 30, 11625-11636.

Dennis, M. S., Henzel, W. J., Pitti, R. M., Lipari, M. T., Napier, M. A., Deisher, T. A., Bunting, S. \& Lazarus, R. A. (1990). Proc. Natl Acad. Sci. USA, 87, 2471-2475.

Fitzgerald, P. A. M. (1988). J. Appl. Cryst. 21, 273278.

Howard, A. J., Gilliland, G. L., Finzel, B. C., Poulous, T. L., Ohlendorf, D. H. \& Salemme, F. R. (1987). J. Appl. Cryst. 20, 383-387.

Huang, T.-F., Holt, J. C., Kirby, E. P. \& Niewiarowski, S. (1989). Biochemistry, 28 , 661-666.

Jancarik, J. \& Kim, S.-H. (1991). J. Appl. Cryst. 24, 409-411.

Navaza, J. (1994). Acta Cryst. A50, 157-163.

Perry, A. F. C., Jones, R., Barker, P. J. \& Hall, L. (1992). Biochem. J. 286, 671-675.

Ruoslahti, E. \& Pierschbacher, M. D. (1987). Science, 238, 491-497.

Saudek, V., Atkinson, R. A. \& Pelton, J. T. (1991). Biochemistry, 30, 7369-7372. 